\title{
A EXPERIENCIA DA CONSTRUÇÃO COLETIVA DE UM CURSO TÉCNICO VOLTADO AOS POVOS INDÍGENAS DO SUDESTE PARAENSE
}

\author{
Tatiana de Oliveira Santana $^{1}$ \\ Elison Antonio Paim²
}

\section{INTRODUÇÃO}

No que diz respeito à teoria educacional, conforme Silva (1999), na última década, antropólogos, sociólogos, pedagogos, indígenas e indigenistas tem procurado sistematizar praticas educativas e construir um conhecimento acerca do fenômeno educacional voltado aos povos indígenas, existindo um campo vasto teórico e metodológico sobre experiências curriculares em educação escolar indígena.

Apresentamos nesse texto, a experiência vivida na cidade de Marabá, região do sudeste paraense, pertencente à Amazônia Oriental Brasileira, na construção inicial de um currículo de curso técnico em agroecologia dos povos indígenas do sudeste paraense, no Instituto Federal de Educação do Pará (IFPA), Campus Rural de Marabá (CRMB) e Conselho Indigenista Missionário (CIMI), que tinha como meta inical, formar 30 jovens técnicos indigenas entre os povos Atikum ${ }^{3}$, Guajajará ${ }^{4}$, Suruí ${ }^{5}$, Asuriní $^{6}$, Amanayé $^{7}$, Akratikatejêe $^{8}$ e Parkatejê,

\footnotetext{
${ }^{1}$ Pedagoga, discente do Programa de Pós-Graduação em Educação, na linha Sociologia e História da Educação, participa do grupo de pesquisa Rastros: História, Memória e Educação, da Universidade São Francisco e do Grupo de Pesquisa Patrimônio, Memória e Educação (PAMEDUC) da UFSC. Desenvolve pesquisa de dissertação sobre narrativas femininas indígenas no ensino superior, orientanda do Prof. Dr. Elison Antonio Paim. E-mail: tati_ubuntu@hotmail.com.

${ }^{2}$ Prof. Dr. Elison Antonio Paim, Professor permanente do Programa de Pós-Graduação em Educação (PPGE), Mestrado Profissional em Ensino de História (Profhistória/UFSC) e de Estágio Supervisionado em História da Universidade Federal de Santa Catarina (UFSC). E-mail: elison0406@gmail.com.

${ }^{3}$ Atikum é autodenominação; são descendentes do grupo Atikum-Umã, "os caboclos da Serra do Umã", do sertão de Pernambuco, aprenderam a dançar o toré com seus vizinhos Falam língua portuguesa; não possuem memória de sua língua originária. Disponível em: < https://pib.socioambiental.org/pt/povo/atikum > Acesso em 08 de maio de 2009.

${ }^{4}$ Tenetehara é autodenominação tradicional do grupo e Guajajara é provavelmente oriundo de alteratribuição por outros povos indígenas. É de tronco linguístico Tupi-Guarani. Os Guajajara são um dos povos indígenas mais numerosos do Brasil. Disponível em: < https://pib.socioambiental.org/pt/povo/guajajara > Acesso em 08 de maio de 2009.

${ }^{5}$ O nome Aikewara, segundo o CEDI (1985), é autodenominação tradicional o grupo; Suruí é uma alter-atribuição provavelmente de Frei Gil Gomes Leitão. Povo de tronco linguístico Tupi-Guarani.

${ }^{6}$ Segundo o CEDI (1985), Akuáwa refere-se à autodenominação tradicional do grupo; Asuriní seria alter-atribuição do antigo Serviço de Proteção do Índio (SPI); Trocará referia-se ao nome do Posto
} 
povos indigenas que estão na região e participaram também na construção do curso, ao qual só foi possível com a organização de um trabalho coletivo e com a corresponsabilidade dos envolvidos num processo educativo.

Na linha reflexiva, a referência a currículo é feita a luz do campo cultural, tomando-o como um movimento, integrando os conhecimentos, respeitando a linguagem, a dinâmica de tempos e espaços, pensando a realidade e trazendo dela novos elementos curriculares, como uma operação de poder compartilhado e dialogado, assim como, Marisa Vorraber Costa (2001, p. 41), afirma:

O currículo e seus componentes constituem um conjunto articulado e normalizado de saberes, regidos por uma determinada ordem, estabelecida em uma arena em que estão em luta visões de mundo e onde se produzem, elegem e transmitem representações, narrativas, significados sobre as coisas e seres do mundo.

Costa (2001), indaga se seremos capazes de pensar um currículo realmente diferenciado, sem praticar alguma forma de violência e se culturas diferentes, podem conversar entre si.

Questionamentos difíceis de responder, onde mesmo imbuídos do querer fazer diferente, operando mudanças radicais nos currículos propostos, partilhamos da ideia dos currículos escolares também serem de acordo com Walter Benjamin (2012), uma forma de barbárie, no sentido do nivelamento sempre numa lógica ocidental e eurocêntrica.

Dessa forma, abordamos o currículo numa perspectiva culturalista, com algumas reflexões que devem ser feitas no sentido de incorrer em ato de violência, logo, devemos nos indagar a quem serve o currículo? Quais interesses estão postos nele? Os indígenas precisam de uma escola para viver ou para viver melhor? $\mathrm{E}$ a que modelo de escola necessitam? As experiências dos atores envolvidos numa construção coletiva, são realmente formativas?

Historicamente, presenciamos processos educativos voltada aos povos indígenas, baseados na dimensão de violência e barbárie, amparados numa visão

Indígena. Segundo o Instituto Socioambiental, há vários anos esse povo adotou o termo Asuriní como autodenominação do grupo. Falam língua de tronco Tupi-Guarani.

7 Amanayé é autodenominação do grupo, que vive no alto curso do Rio Capim, e falam língua de tronco Tupi-Guarani (CEDI, 1985).

${ }^{8}$ Os nomes desses três povos - Parkatêjê, Kyikatêjê, Akrãtikatêjê - são autodenominações. São alter-denominados pelos "brancos" como Gavião (denominação que viajantes atribuíram a diferentes grupos Timbira). Falam língua de tronco Jê. Disponível em: < https://pib.socioambiental.org/pt/povo/gaviao-parkateje> Acesso em 08 de maio de 2009. 
eurocêntrica de educação, que contribuem com o tutelamento à autodeterminação desses sujeitos, que desrespeitam suas cosmologias e cosmogonias acerca de suas sociedades, dessa forma, não contribuindo com seus projetos societários, autoafirmação e valorização dos seus conhecimentos.

Nesse sentido, apresentamos aqui, a experiência dos dois primeiros anos, que foram o de construção da proposta curricular de curso, onde mesmo sendo centralizada na "escola" e partindo de uma educadora responsável pela proposta de curso na época, os passos iniciais, a construção do currículo, aproximam-se de alternativas possíveis contra a dominação, desigualdade e exclusão vivida historicamente por esses povos.

Os dados apresentados neste texto, são do ano de 2009/2010, porém contribuem no entendimento a uma dada realidade dos povos indígenas do sudeste paraense, sobre as realidades educacionais e desafios territoriais enfrentados por esses povos, elementos que contribuíram na reflexão de uma proposta curricular diferenciado, que atendesse as diversas realidades dos povos envolvidos.

Percebemos uma necessidade de narrar essa experiência, por consideramos formativa e importante no entendimento das realidades dos povos indígenas do sudeste paraense, afinal, dialogando com o pensamento de Walter Benjamin, ao questionar "qual o valor de todo o nosso patrimônio cultural, se a experiência não mais o vincula a nós?" (2012, p. 124).

\section{APRESENTANDO ALGUNS DADOS SOBRE OS POVOS INDÍGENAS NO SUDESTE PARAENSE ${ }^{9}$}

Dos povos indígenas que compõe a mesorregião do sudeste paraense são constituídos por aproximadamente 12 povos (Amanayé, Akuáwa-Asurini do Trocará, Aikewara-Suruí, Xikrin do Catete $^{10}$, Tenetehara-Guajajara, Karajá ${ }^{11}$,

\footnotetext{
${ }^{9}$ Cumprem assinalar que parte desse texto faz parte do PPP do Curso técnico em agroecologia dos povos indígenas do sudeste paraense, documentos do IFPA/CRMB.

${ }^{10} \mathrm{~A}$ autodenominação específica dos Xikrin do Cateté é Putkarôt, nome que atualmente não usam mais. Hoje eles se consideram Xikrin, nome dado a eles pelos brancos. (CEDI, 1985, 123).

${ }^{11} \mathrm{O}$ nome originário do povo é Iny. "O nome Karajá não é a autodenominação original". É um nome tupi que se aproxima do significado de "macaco grande". Disponível em: < http://pib.socioambiental.org/pt/povo/karaja/364> Acesso em 08 de maio de 2009.
} 
ebêngôkre-Kayapó ${ }^{2}$, Guarani-Mbya e Guarani-Ñandeva, Parkatêjê, Kyikatêjê, Akrãtikatêjê e Atikum) e 27 aldeias, cujas línguas originárias são de tronco TupiGuarani e Jê. Existem povos que são nativos, ocupam ancestralmente o território regional, e outros que sofreram deslocamentos recentes ou mais antigos, dentre eles Atikum (originário de Pernambuco), Guajajara (originário do Maranhão), Guarani (vários deslocamentos) e Parkatêjê, Kyikatêjê, Akrãtikatêjê (originários do Maranhão), seja por influência de seus projetos societários, cosmológicos e culturais. Como é o caso de muitos grupos tupi, que saem em busca da Terra Sem Males; em busca de lugares que visualizam e percebem ser de seus espíritos ancestrais, entre outros, seja por processos de desterritorialização resultado do avanço do capital nas terras indígenas. (IFPA/CRMB, 2010)

$\mathrm{Na}$ construção do curso, foram estabelecidos diálogos com comunidades e lideranças indígenas de sete povos (Atikum, Guarani, Aikewara-Suruí, Amanayé, Guajajara, Assuriní, Akrãtikatêjê e Kyikatêjê), aos quais traremos dados educacionais e de seus territórios para posterior analises.

Logo, em respeito, inclusive, ao que determina a legislação sobre a prerrogativa desses povos de participação e decisão sobre suas próprias prioridades de desenvolvimento. Por exemplo, o Art. 27 da Convenção 169 da Organização Internacional do Trabalho (OIT) de 1989 (Sancionada pelo Decreto Presidencial № 5.051, de 19 de abril de 2004), prevê que:

Programas e serviços de educação destinados a esses povos deverão ser desenvolvidos e aplicados em cooperação com eles, a fim de atender às suas necessidades particulares, e deverão abranger sua história, seus conhecimentos e técnicas, seus sistemas de valores e, mais ainda, suas aspirações sociais, econômicas e culturais.

Um dos critérios que jamais foi desconsiderado, na construção da proposta de curso técnico, foi a participação dos povos indígenas envolvidos, formando dessa forma, o maior diferencial do curso, onde os passos adotados foram norteados por preceitos de respeito as vozes e experiencias desses sujeitos.

Atualmente, o reconhecimento e legitimação dos territórios e das culturas indígenas, a partir da demarcação, criação de reservas e sustentabilidade, tem sido um dos principais anseios dos povos indígenas e de entidades indigenistas, ocorre,

\footnotetext{
${ }^{12}$ Mebêngôkre é autodenominação tradicional do grupo; Kayapó passou a ser utilizado a partir de alter-atribuição de outros povos indígenas. Disponível em: < http://pib.socioambiental.org/pt/povo/kayapo/177> Acesso em 08 de maio de 2009.
} 
no entanto, que, as demarcações oficializadas por órgãos governamentais não suprem as necessidades dos povos indígenas por serem áreas pequenas, dificultando as condições de gestão sustentável dos territórios e a soberania alimentar, ficando os indígenas suprimidos em reservas menores que suas áreas anteriores, ou até mesmo, perdendo parte dos territórios dificultando a valorização e a reprodução cultural desses povos. Podendo ser conferido no quadro abaixo que apresenta os povos/aldeias visitados pelo IFPA/CRMB.

Quadro 01: Extensão Territorial das Aldeias Visitadas

\begin{tabular}{|c|c|c|c|c|c|c|}
\hline Nome & Aldeia & Município & $\mathbf{N}^{\circ}$ de Família & População & Extensão (ha) & Área \\
\hline Atikum & Canaí & Canaã dos Carajás & 5 & 27 & 50 & Assentamento \\
\hline Atikum & Ororuba & Itupiranga & 15 & 63 & 1160 & Assentamento \\
\hline \multirow{2}{*}{ Suruí } & Sororó & São João & 70 & 340 & \multirow{2}{*}{26.258} & \multirow{2}{*}{ Terra indígena } \\
\cline { 2 - 6 } & Itahi & São João & 08 & 37 & & Terra indígena \\
\hline Guarani & Mybá & Jacundá & 09 & 46 & 490 & Terra indígena \\
\hline Amanayé & Barreirinha & Paragominas & 22 & 151 & 4.500 & Assentamento \\
\hline Guajajara & Guajanaíra & Itupiranga & 15 & 66 & 1346 & \\
\hline
\end{tabular}

Fonte: Relatório de visita as Comunidades Indígenas: Canaí, Ororuba, Barreirinha, Sororó, Itahi, Guajanaíra e Guarani, IFPA \& CIMI, 2009.

Notoriamente, a demarcação das terras indígenas de uma forma geral, não tem representado o sinônimo de proteção e continuidade das tradições, visto terem desafios relacionados ao manejo e gestão de seus territórios e recursos, bem como ameaças de invasões destes territórios por madeireiros, pescadores, fazendeiros, caçadores bem como os grandes projetos de mineração e hidrelétricos da região.

As comunidades indígenas visitadas representam uma diversidade de situações, tanto no que se refere à extensão, gestão dos territórios e a produção agropecuária, quanto às questões socioculturais, ligados à organização e a representação das práticas e dos costumes.

O contato com essa realidade diversa nos permitiu ter a compreensão de que há dois tipos de situações bem distintas entre as comunidades indígenas, principalmente a partir da compreensão da gestão e organização do território.

A primeira, relacionada às comunidades indígenas que possuem uma gestão de seu território semelhante há agricultores familiares/camponeses. Em geral 
essas comunidades estão situadas dentro de projetos de Assentamentos da Reforma Agrária, possuindo os mesmos direitos e obrigações que os demais agricultores assentados. A produção é individualizada cada família detém o seu espaço e os seus bens de produção, as principais atividades desenvolvidas estão relacionadas ao cultivo de roçados e a criação de gado, tanto com aptidão leiteira, quanto para carne.

A segunda, diz respeito às comunidades indígenas que possuem uma gestão tradicional de seus territórios. Em geral as aldeias são demarcadas, possui uma lógica de produção baseada na gestão coletiva, têm como principais ameaças os grandes projetos, pesca profissional, caça predatória e madeireiros. E, em geral as aldeias possuem maiores extensões e são mais populosas do que as comunidades indígenas descritas na primeira situação.

Os principais limites e desafios que enfrentam as comunidades indígenas classificadas no primeiro grupo, no que consiste a gestão do território e dos recursos naturais, dizem respeito à centralidade da pecuária nas atividades produtivas das famílias. Neste sentido, enfrentam os mesmos desafios de camponeses da região que possuem limitado território, desenvolveram a pecuária, estão com as pastagens degradadas, com pouca disponibilidade de área para o cultivo de roçados e encontram-se diante do desafio da sustentabilidade ambiental e, em médio prazo, também socioeconômica. Outra questão é a dificuldade na comercialização dos produtos ocorrendo principalmente em função da falta de infraestrutura de produção básicas, como: estradas, transporte e beneficiamento. (IFPA/2010).

Em relação a dados educacionais em quase todas as aldeias visitadas existe escolas, mas não estão regularizadas como escolas indígenas, são anexos de Escolas Municipais de Ensino Fundamental e Médio dos seus municípios de origem. Não tem currículo e nem material especifico, há professores não indígenas, atuando em todos os segmentos de ensino, mas apresentado demandas significativas para o ensino médio. Os professores indígenas são contratados pelas secretárias de educação dos municípios e atuam com a valorização da língua e cultura. Afirmando as dificuldades de efetivação das leis citadas neste texto acima que garantem uma educação diferenciada e especifica. A educação é colocada pela maioria dos moradores das aldeias como ação prioritária, porém há uma necessidade imediata de estruturar a escola, legalizar enquanto escola indígena, ampliando o espaço físico e o acesso aos recursos didáticos específicos. Assim como a adequação do 
currículo da escola a realidade das aldeias, proporcionar a participação da juventude e adultos em projetos de educação escolar indígena, sendo esta uma ação que poderá estimular a permanência da juventude na aldeia e a troca de informações sobre a produção, sustentabilidade, cultura e outros.

A gestão sustentável de suas terras é vista pelos indígenas como uma questão que precisa ser profundamente debatida, principalmente em função do aumento no número de habitantes e consequentemente a maior pressão sobre os recursos naturais ora ameaçados pelos grandes projetos, ora por madeireiros, pescadores e fazendeiros. Dessa forma, necessitam de ações que possam contribuir com a comunidade atividades produtivas diversificadas e com baixo impacto ao meio ambiente. Outra questão são as constantes invasões aos territórios indígenas e ameaça de madeireiros, fazendeiros e pescadores, o que tem gerado tensões nas aldeias e o futuro comprometimento dos recursos naturais.

As visitas às aldeias possibilitaram identificarmos sujeitos com profundo conhecimento sobre a cultura indígena (história das aldeias, ritos, crenças, língua, caça, pesca, agricultura indígenas e outros), em seus mais distintos papeis sociais (professores indígenas, caciques, lideranças políticas, pajés, guerreiros e outros).

Portanto, eis o desafio de formulação e execução de políticas públicas que Ihes dizem respeito, onde haja uma formação voltada ao desenvolvimento de atividades norteadas pelos preceitos da sustentabilidade, etica, da não geração de dependência tecnológica e econômica, com enfoque à proteção das Terras Indígenas e a valorização dos conhecimentos e técnicas destes povos.

\section{O PROCESSO DE CONSTRUÇÃO DO CURSO}

Foram desenvolvidas na elaboração deste projeto de curso, atividades de visitas locais às aldeias, construção de relatórios específicos a cada povo, realização de dois seminários regionais com lideranças e professores indígenas, uma formação aos educadores do CRMB em educação escolar indígena e diálogos com parceiros e estudo de pesquisas e documentos sobre os povos indígenas da região.

Dos povos acima apresentados, 28 lideranças e/ou professores indígenas participaram do I Seminário Regional IPFA - Povos Indígenas (2009), realizado para discutir o projeto de curso. Nesta atividade, apresentamos e 
discutimos a leitura da realidade, realizada pelos professores do CRMB, sobre as aldeias visitadas e quais os elementos que utilizamos como referência para elaborar a proposta de curso ora apresentada. Os participantes consideraram pertinentes os elementos das realidades nos quais havíamos fundamentado a construção da proposta de curso, bem como reagiram positivamente à proposição da metodologia da alternância pedagógica Tempo-Escola e TempoAldeia. ${ }^{13}$

Num segundo momento coletivo de construção do curso, foi realizado, conjuntamente com o CIMI, o II Seminário dos Povos Indígenas e CRMB, o qual teve como foco, responder as demandas mais específicas, que subsidiassem a implantação do Curso, como o ementário do curso, critérios de seleção dos educandos da primeira turma, regimento interno, calendário das alternâncias tempo-escola entre outras demandas mais práticas para o início do curso.

Em terceiro momento, foi realizado nas aldeias o processo seletivo dos candidatos ao curso, onde novamente se conversava com as lideranças e os sábios das aldeias no sentido de reafirmar o que já vinha sendo desenvolvido coletivamente entre os povos indígenas, o CIMI e o CRMB a respeito do curso. Os jovens ali, neste momento do processo seletivo, assumiam o compromisso também perante seu povo em participar deste curso.

Essas ações oportunizaram, uma relação direta com os povos indígenas, fornecendo elementos sobre a realidade educacional, política e territorial das comunidades e contribuindo com uma formação especifica em educação escolar indígena aos educadores do instituto.

Sendo, os indígenas, os demandantes da proposta construída, e não somente consultados no processo da construção do curso. Por outro lado, todos os professores envolvidos, ao participarem das formações eram "alfabetizados" no sentido de reconhecer as diferenças de cada povo, a partir das colocações de cada indígena nos encontros, percebendo as diferentes linguagens de cada povo, a dinâmica de tempos e espaços desses povos indígenas ali presentes. Ouvindo elementos a partir das narrativas, que possibilitavam, pensar a realidade de cada aldeia e trazendo dela novos elementos curriculares, desenvolvendo reflexões/

\footnotetext{
${ }^{13}$ Adotamos a Metodologia da alternância, utilizando o termo tempo aldeia, momento em que os jovens indígenas estariam em suas comunidades, desenvolvendo suas pesquisas em sua vivencias cotidianas com seu povo.
} 
ações, a um currículo integrado, não somente nos conteúdos, mas, integrados aos sujeitos participantes.

Consideramos esses encontros de formulação da proposta, como fundamental ao respeito a diversidade, onde as falas dos povos indígenas nesses momentos, traziam elementos para repensar as práticas enquanto educadoras/es nesse curso, apreendendo nesses processos formativos a não ofender com o silenciamento esses sujeitos, valorizando as potencialidades, percebendo outros conhecimentos além dos conhecimentos acadêmicos e específicos de cada área.

E neste fazer do processo de construção do curso, arriscamos afirmar, que ali naqueles encontros, sejam nas aldeias ou nos grupos de discussão, de ementas, quantidade de vagas por povo, processo seletivo, na escolha do nome do curso, dos desafios de cada aldeia presente em cada fala dos sábios, o pressuposto da interculturalidade de acordo com Walsh, (2009) ocorria, fazendo a proposta curricular ser dialogada, construindo um currículo em movimento. Defendemos o currículo, numa proximidade ao pensamento de Macedo (2006), entendendo-o como movimento, sendo hibrido e cultural, que, "nesse híbrido as tramas oblíquas de poder tanto fortalecem certos grupos como potencializam resistências" (Macedo, 2006, p. 290). Portanto, dialogar sobre o processo de construção do curso, aproximávamos de uma das ações possíveis de desterritorialização do conhecimento dominante, que historicamente se colocam aos povos indígenas como o único possível.

\section{A PROPOSTA CURRICULAR}

A organização curricular do curso incluiu disciplinas do Ensino Médio, como prevê a Base Nacional Comum ${ }^{14}$, e do Técnico. Os conteúdos exigidos no Ensino Médio foram ministrados de forma integrada e articulados com os previstos no Ensino Técnico.

A alternância dos tempos-espaços educativos contemplou a carga horária mínima definida para o curso. O Tempo-Espaço Escola foi desenvolvido pelos professores do IFPA/CRMB, com a participação de membros das

\footnotetext{
${ }^{14}$ A Base Nacional apresenta os conteúdos mínimos e a carga horária a serem vistos em sala de aula para as áreas de linguagem, matemática, ciências da natureza e ciências humanas em cada etapa escolar do estudante.
} 
comunidades, e o Tempo-Espaço Aldeia também contará com visitas periódicas dos professores às comunidades indígenas, visando acompanhar 0 desenvolvimento das atividades dos estudantes nas aldeias, conviver com a comunidade e dialogar com as lideranças indígenas.

O currículo do curso referencia-se no Eixo Articulador Sustentabilidade dos Territórios Indígenas, desdobrando-se em Eixos Temáticos, de modo a contemplar a diversidade das realidades das comunidades e realização da interdisciplinaridade e do diálogo de saberes: a) Cultura e Identidade; b) Terra, Trabalho e produção; c) Organização Social e d) Direitos e Políticas Públicas.

Esses eixos temáticos, objeto de pesquisa e estudo durante os ciclos de formação seriam as referências para a construção dos Planos de Estudo, Pesquisa e Trabalho, sendo que no primeiro ciclo estariam articulados à construção de diagnósticos das realidades, no segundo ciclo ao estudo dos sistemas de produção e, no terceiro, à discussão das perspectivas de etnodesenvolvimento e políticas públicas.

Dessa forma, procuraria cumprir o que é determinado pela própria LDB\96 que tem o pressuposto de que a educação deve vincular-se ao mundo do trabalho e a prática social. Ressaltando que embora o ensino médio tivesse tradicionalmente o trabalho como princípio educativo e ligado ao socialmente produtivo, a perspectiva adotada neste curso está ligada ao conceito de ciência e cultura, no qual, o trabalho indicará uma relação com a materialidade concreta que o constitui, levando em consideração o sentido de entender e transformar fenômenos naturais e culturais considerando as diferenças culturais e sociais de acordo com o que o movimento indígena vem chamando de "projetos de futuro" dos povos e comunidades.

\section{CONSIDERAÇÕES FINAIS}

Os indígenas precisam de uma escola diferenciada, mas não somos nós, que devemos propor o que é essa diferença, cabe, portanto, ouvi-los e buscar compreender o que representa e o que buscam na escola. Quando propomos ou desprestigiamos um modelo de escola focada nos interesses indígenas, estamos, de certa forma, estabelecendo uma relação de poder, desrespeitando suas 
características tradicionais e a liberdade de escolha e não contribuindo com os projetos societários, algumas vezes, desconsiderando as especificidades de cada povo.

Desenvolver currículos de cursos voltados as comunidades indígenas, ainda enfrentam grandes desafios metodológicos no sentido de oportunizar uma educação escolar indígena dialogada e construída com os próprios sujeitos, que devem ser demandantes de formação a partir de seus projetos societários. Nos quais, as propostas sejam fundamentadas nas leis específicas e nas realidades de cada povo, com conteúdo relacionando com a vida de cada povo indígena, adotando a pesquisa como princípio educativo como uma extensão do cotidiano, relacionado com as práticas culturais de cada povo e as experiências próprias dos grupos/unidades familiares, na garantia da sustentabilidade permanência em seus territórios.

Nesse sentido, é interessante pensar formas, metodologias, procedimentos próprios e peculiares, do cotidiano das sociedades indígenas que precisam ser potencializados, respeitando as especificidades dos processos de saber-fazer próprios. Dessa forma não se consideraria somente a escolarização para os povos que dispõem desse processo em suas vidas, mas os diferentes níveis e relações com os processos de escolarização, no espaço, com a sociedade envolvente e na vida nas aldeias. Afinal, existem outros processos que fundamentam a reprodução sociocultural desses grupos que não estão colocados nos currículos tradicionais das escolas. E, se o currículo é o que dá identidade à escola, sua construção, seleção, organização do conteúdo é uma operação de poder, podemos agir de adotando posturas mais participativas e dialógicas junto aos povos indígenas.

\section{REFERÊNCIAS}

BENJAMIN, Walter. Obras escolhidas. Vol. 1. Magia e técnica, arte e política. Ensaios sobre literatura e história da cultura 8를 Edção. São Paulo. Brasiliense, 2012 - (Obras Escolhidas v.1).

BRASIL, Constituição (1988). Constituição da República Federativa do Brasil: promulgada em 5 de outubro de 1988

CEDI/, Museu Nacional/ UFRJ. Terras Indígenas no Brasil. São Paulo: Tipografia Marca, 1987. 
CIMI, A violência contra os povos indígenas no Brasil. 2003-2005. Brasília, 2006.

CONSELHO NACIONAL DE EDUCAÇÃO, 5o documento técnico, requerido pelo Termo de Referência do Projeto 914 BRA 1119, em parceria com a Unesco.

COSTA, Marisa Vorraber. 0 currículo nos limiares do contemporâneo. Org. $3^{a}$ Edição, Rio de Janeiro. DP\&A,2001.

HALL, Stuart. A identidade cultural na pós-modernidade. $3^{a}$. ed. Trad. Tomaz Tadeu da Silva e Guacira Lopes Louro. Rio de Janeiro: Ed. DP\&A, 1997.

IBGE, Censo Demográfico Brasileiro. Rio de Janeiro, 2000.

IFPA/CRMB. Projeto Político Pedagógico: Curso Técnico em Agroecologia Integrado ao Ensino Médio dos Povos Indígenas do Sudeste Paraense. 2010.

Instituto Federal de Educação, Ciência e Tecnologia do Pará (IFPA) - Campus Rural de Marabá (CRMB) \& Conselho Indigenista Missionário (CIMI). Relatório de Visita ao Povo Amanayé Barreirinha. Marabá, 2009.

Instituto Federal de Educação, Ciência e Tecnologia do Pará (IFPA) - Campus Rural de Marabá (CRMB) \& Conselho Indigenista Missionário (CIMI). Relatório de Visita ao Povo Atikum Canaí. Marabá, 2009.

Instituto Federal de Educação, Ciência e Tecnologia do Pará (IFPA) - Campus Rural de Marabá (CRMB) \& Conselho Indigenista Missionário (CIMI). Relatório de Visita ao Povo Atikum Ororubá. Marabá, 2009.

Instituto Federal de Educação, Ciência e Tecnologia do Pará (IFPA) - Campus Rural de Marabá (CRMB) \& Conselho Indigenista Missionário (CIMI). Relatório de Visita ao Povo Guajajará Guajanaíra. Marabá, 2009.

Instituto Federal de Educação, Ciência e Tecnologia do Pará (IFPA) - Campus Rural de Marabá (CRMB) \& Conselho Indigenista Missionário (CIMI). Relatório de Visita ao Povo Guarani Mbya. Marabá, 2009.

Instituto Federal de Educação, Ciência e Tecnologia do Pará (IFPA) - Campus Rural de Marabá (CRMB) \& Conselho Indigenista Missionário (CIMI). Relatório de Visita ao Povo Suruí Sororó. Marabá, 2009.

Instituto Federal de Educação, Ciência e Tecnologia do Pará (IFPA) - Campus Rural de Marabá (CRMB) \& Conselho Indigenista Missionário (CIMI). Relatório de Visita ao Povo Suruí Itahy. Marabá, 2009.

INSTITUTO SÓcIO AMBIENTAL, Povos Indígenas No Brasil. Disponível: https://pib.socioambiental.org/pt. Acesso em 16/05/2016.

MACEDO, Elizabeth. Currículo como espaço Currículo como espaço-tempo de fronteira cultural. Revista Brasileira de Educação, v. 11, n. 32, p. 285, 2006. 
MEC. Educação como exercício de diversidade. - Brasília: UNESCO, ANPEd, 2005. 476 p. - (Coleção educação para todos; 6).

PAIM, Elison Antonio. NAGLE, Liane Maria. HENTZ, Maria Izabel de Bortolli. Espaços para 0 fazer-se professor (a): A experiência do Pibid- diversidade em escolas indígenas de Santa Catarina e do Rio Grande do Sul. Atos de Pesquisa em Educação. Revista do Programa de Pós-Graduação em Educação da Universidade Regional de Blumenau (PPGE/FURB). V. 10, n. 2, p. 436-461, mai/ago.2015.

RODRIGUES, Aryon Dall'Igna. Línguas Brasileiras, Edições Loyola. São Paulo, SP, 1986.

SILVA, Tomaz Tadeu. Documentos de Identidade: uma introdução às teorias do currículo. Belo Horizonte: Editora Autêntica, 1999.

WALSH, Catherine. Interculturalidade crítica e pedagogia decolonial: in-surgir, reexistir e re-viver. In: CANDAU, Vera Maria (Org.). Educação intercultural na América Latina: entre concepções, tensões e propostas. Rio de Janeiro: 7 Letras, 2009. p. $12-43$. 